\title{
HUBUNGAN PSYCHOLOGICAL DISTRESS DAN KARAKTERISTIK INDIVIDU, KELUARGA DAN LINGKUNGAN KERJA PADA TENAGA KERJA WANITA (TKW) INDONESIA DI TAIWAN
}

\author{
Bianca Marella \\ Fakultas Psikologi, Universitas Tarumanagara, Jakarta \\ Email: biancam@fpsi.untar.ac.id
}

Masuk:11-04-2019, revisi: 24-09-2019, diterima untuk diterbitkan : 25-09-2019

\begin{abstract}
ABSTRAK
Belum banyak upaya dilakukan untuk mengetahui kesehatan mental tenaga kerja wanita yang berada di luar negeri. Penelitian ini bertujuan untuk melihat gambaran dan faktor-faktor yang berhubungan dengan kesehatan kesehatan mental pada Tenaga Kerja Indonesia yang bekerja di Taiwan. Data diambil menggunakan metode kuantitatif dengan alat ukur the Hopkins Symptoms Checklist-25 (HSCL-25) untuk mengetahui tingkat distres psikologis dan pertanyaan mengenai karakteristik sosiodemografik. Partisipan penelitian ini adalah 181 tenaga kerja wanita Indonesia yang sudah bekerja di Taiwan selama minimal enam bulan, dikumpulkan dengan teknik convenience sampling dan snowball sampling. Berdasarkan penghitungan statistik, sebanyak $17 \%$ dari total partisipan mengalami gejala depresi dan kecemasan. Dari uji hipotesis, diketahui terdapat hubungan positif signifikan antara distres psikologis dan komunikasi rutin dengan keluarga, keaktifan di komunitas, dan alasan kerja untuk mencari kesempatan lebih baik.
\end{abstract}

Kata Kunci: kesehatan mental, Indonesia, tenaga kerja wanita, psychological distress

\begin{abstract}
Little effort has been made to find out the mental health of women workers who are abroad. This study aims to look at the picture and factors related to mental health health in Indonesian Workers who work in Taiwan. Data were collected using quantitative methods using the Hopkins Symptoms Checklist-25 (HSCL-25) to determine the level of psychological distress and questions about sociodemographic characteristics. The participants of this study were 181 Indonesian female workers who had worked in Taiwan for a minimum of six months, collected using convenience sampling and snowball sampling techniques. Based on statistical calculations, as many as $17 \%$ of the total participants experienced symptoms of depression and anxiety. From the hypothesis test, it is known that there is a significant positive relationship between psychological distress and routine communication with family, activity in the community, and the reasons for work to look for better opportunities.
\end{abstract}

Keywords: mental health, Indonesia, female labor, psychological distress

\section{PENDAHULUAN}

\section{Latar Belakang}

Kesehatan migran merupakan masalah yang penting di masyarakat. Saat ini, diperkirakan 150 juta pekerja migran bekerja di negara-negara selain negara kelahiran mereka (IOM, 2015). Buruh migran memainkan peran penting dalam mempromosikan pertumbuhan ekonomi di negara-negara penerima dengan mengisi kesenjangan tenaga kerja dan keterampilan. Terlepas dari upaya yang dilakukan untuk memastikan perlindungan mereka, pekerja migran tetap rentan dan menanggung risiko signifikan bagi kesehatan sosial dan mental mereka sepanjang siklus migrasi (Bhugra, 2004; IOM, 2012). Studi sebelumnya menunjukkan bahwa paparan berbagai jenis kerentanan di negara tujuan, seperti pemisahan dari keluarga (Jurado, 2017; Schmalzbauer, 2004), kondisi kerja yang keras (Chin, 1997), kurangnya akses ke layanan kesehatan (Calderon, 2012) dan perlindungan hukum (Chin, 1997), meningkatkan risiko untuk depresi dan kecemasan di antara pekerja migran. Dampak gangguan mental, termasuk depresi dan kegelisahan, meresap dan bertahan lama. Ini juga membebankan biaya besar pada individu, keluarga dan masyarakat secara keseluruhan. Semua 
pihak dapat menderita kekurangan ekonomi dan sosial karena berkurangnya produktivitas yang dapat mengakibatkan pemutusan hubungan kerja (WHO, 2001).

Migrasi di Asia telah tumbuh dengan laju 1,5 juta migran internasional per tahun antara 2010 dan 2015 (UN, 2016). Migrasi internasional telah menjadi kekuatan penting bagi pertumbuhan dan pembangunan ekonomi bahkan di kawasan Asia Timur yang dinamis (World Bank, 2014). Kesenjangan yang lebar dalam pendapatan rata-rata di seluruh negara di kawasan, pada urutan 5 hingga 10 kali, membuat negara-negara Asia Timur, seperti Taiwan, rumah bagi negara-negara "pengirim tenaga kerja" (World Bank, 2014). Tenaga kerja wanita berkontribusi hampir separuh (48.7\%) dari keseluruhan jumlah tenaga kerja migran usia produktif yang berasal dari negara ASEAN. Peningkatan permintaan tenaga kerja untuk sektor feminin seperti sektor kesehatan, pekerjaan rumah tangga, sektor hiburan, sektor pabrik dan tekstil untuk negara-negara tujuan di Asia seperti Taiwan, Hong Kong, Malaysia, dan Singapura; disertai dengan berkurangnya lapangan pekerjaan purnawaktu bagi pria, menarik banyak wanita untuk memutuskan bekerja sebagai tenaga kerja migran guna menafkahi nafkah keluarga dan komunitas mereka.

Indonesia merupakan salah satu negara pemasok tenaga kerja migran di dunia, terutama ke negaranegara Asia dan Timur Tengah. Pada akhir 2015, pekerja Indonesia menyumbang 40\% dari total jumlah pekerja migran di Taiwan, dibandingkan dengan Vietnam (29\%), Filipina (21\%), dan Thailand (10\%) (Taiwan National Statistics Bureau, 2015).

Beberapa upaya dan perhatian akan kesehatan pekerja migran sudah dilakukan di Taiwan. Namun, kendati pekerja migran Indonesia memegang populasi pekerja migran terbesar di Taiwan, perhatian mengenai kesehatan mental bagi mereka masih kurang. Kesehatan mental yang buruk dapat mempengaruhi kinerja pekerja migran, yang kemudian berefek pada penurunan produktifitas yang berpotensi mendatangkan kerugian bagi pemilik usaha. Penelitian sebelumnya membahas kondisi pekerja migran di Taiwan dengan menggunakan pendekatan kualitatif, seperti etnografi institusional, untuk mengeksplorasi kondisi kerja dalam kerangka kebijakan melalui pengalaman individu yang diperoleh dari pengamatan dan wawancara pribadi (Lan, 2006; Liang, 2015; Loveband, 2004). Lan Pei-Chia (2006) mengkaji kondisi hidup dan aturan kerja pekerja migran dari ranah hokum, sementara Anna Loveband (2004) mendeskripsikan bagaimana agen penyalur migran di Taiwan mengembangkan stereotip pekerja migran berdasarkan kewarganegaraan. Kesehatan mental dan informasi mengenai faktor-faktor terkait tidak diketahui dengan pasti. Oleh karena itu, penelitian ini bertujuan untuk mengetahui gambaran gejala depresi dan kecemasan tenaga kerja wanita Indonesia di Taiwan dengan menggunakan alat yang divalidasi, serta untuk mengeksplorasi karakteristik individu, keluarga dan lingkungan kerja yang mungkin terkait dengan kesehatan mental tenaga kerja wanita Indonesia di Taiwan.

\section{Rumusan Masalah}

Peneliti ingin mengetahui apakah terdapat hubungan yang signifikan antara distres psikologis dengan karakteristik individu, keluarga dan lingkungan kerja pada individu tenaga kerja wanita Indonesia yang bekerja di Taiwan. Selain itu, penelitian ini juga ingin mengetahui gambaran distres psikologis yang dialami oleh individu.

\section{METODE PENELITIAN}

Penelitian ini dilakukan di negara Taiwan, tepatnya kota Taipei dan Kaohsiung, antara bulan Juli dan November 2015. Peneliti mengunjungi tempat-tempat yang biasa digunakan pekerja migran dari berbagai tempat untuk berkumpul di hari libur, seperti Stasiun Pusat Taipei (Taipei Main 
Station) dan tiga taman kota di Kaohsiung. Kaji etik penelitian diperoleh dari Institutional Review Board (IRB) dari National Yang-Ming University di Taipei. Total jumlah partisipan penelitian adalah 181 tenaga kerja wanita Indonesia.

\section{Alat ukur penelitian}

Penelitian ini menggunakan metode kuantiatif dengan kuesioner dalam Bahasa Indonesia. Penerjemahan dilakukan pertama oleh peneliti, dan kemudian dilakukan uji keterbacaan awal dengan seorang dokter dari Indonesia dan dua orang aktivis masyarakat di organisasi lokal. Instrumen ini kemudian diujicobakan kepada sepuluh pekerja migran yang memenuhi syarat sebagai partisipan studi untuk memastikan keterbacaan. Berdasarkan umpan balik dari proses ini, peneliti membuat beberapa perubahan dalam pilihan kata dan menambahkan opsi untuk sektor pekerjaan untuk menambah kejelasan.

\section{Kondisi kesehatan mental}

Kesehatan mental diukur menggunakan alat ukur the Hopkins Symptoms Checklist - 25 (HSCL25). Instrumen ini telah digunakan di dalam studi mengenai migran di berbagai negara, termasuk Indonesia (Turnip, 2007; Turnip, 2010). Kami menggunakan batas skor 1.75 untuk menentukan potensi distress, dengan pengertian skor di atas 1.75 mengindikasikan individu tersebut berpotensi membutuhkan pemeriksaan mental lebih lanjut. Rincian proses validasi budaya dari alat ukur HSCL-25 dalam konteks Indonesia dapat ditemukan di penelitian lain (Turnip, 2007). HSCL-25 mengukur gejala depresi dan kecemasan dalam seminggu terakhir, dengan menanyakan seberapa mengganggu keluhan yang mereka rasakan dalam item-item pernyataan dengan contoh sebagai berikut: perasaan takut yang mendadak tanpa sebab; merasa gugup; perasaan tegang atau terpaku (Derogatis, 1974). Total item sebanyak 25 pernyataan dengan skala penilaian mulai dari 1 (tidak sama sekali) hingga 4 (sangat). Konsistensi internal yang diukur oleh Cronbach $\alpha$ adalah 0,89 untuk subskala depresi dan kecemasan.

\section{Karakteristik sosio-demografi}

Variabel demografis termasuk usia, tingkat pendidikan, status perkawinan, pekerjaan sebelumnya dan ada atau tidaknya makanan pantangan.

\section{Karakteristik keluarga}

Peserta ditanyai pertanyaan mengenai kondisi keluarga mereka saat ini: apakah peserta memiliki anak, usia anak, status pekerjaan pasangan, dan frekuensi serta metode yang digunakan untuk menghubungi keluarga. Frekuensi komunikasi dengan keluarga dibagi dalam empat kategori: sekali per hari, sekali per minggu, sekali per bulan dan tidak rutin.

\section{Karakteristik kerja}

Karakteristik kerja terdiri dari jenis pekerjaan, lokasi kerja, durasi kerja, dan akomodasi berkenaan dengan pembatasan diet, praktik keagamaan dan aktivitas sosial di tempat kerja mereka.

\section{Analisis statistik}

Analisis data eksplorasi dilakukan menggunakan korelasi Chi-square dan Pearson untuk menilai potensi pembaur dan kolinearitas antara variabel. Selanjutnya, analisis linear regresi digunakan untuk menyelidiki faktor-faktor yang terkait dengan distres psikologis. Tingkat distres psikologis adalah variabel dependen dan analisis dilakukan secara terpisah untuk karakteristik pribadi, keluarga dan lingkungan kerja. Nilai 1,75 digunakan untuk mengkategorikan kondisi distress psikologis yang tinggi dan rendah. Frekuensi kontak keluarga dikelompokkan sebagai "rutin", termasuk sekali per hari, sekali per minggu, sekali per bulan, dan "tidak rutin". Untuk setiap 
kelompok karakteristik, analisis murni dan terkontrol dilakukan. Tingkat alfa dua sisi 0,05 dianggap signifikan secara statistik. Analisis dilakukan dengan menggunakan perangkat lunak statistik STATA versi 15.0 (College Station, TX: StataCorp LP. 2017).

\section{HASIL DAN PEMBAHASAN}

\section{Karakteristik partisipan}

Karakteristik demografi, keluarga dan pekerjaan partisipan penelitian ditunjukkan pada Tabel 1. Partisipan penelitian ini adalah 181 tenaga kerja wanita Indonesia yang bekerja di Taiwan. Ratarata usia partisipan adalah 30 tahun ( $S D=6,6$ tahun). Sebanyak 73 peserta $(40 \%)$ telah menyelesaikan sekolah menengah atas atau pendidikan tinggi dengan rata-rata tahun pendidikan adalah 10 tahun ( $\mathrm{SD}=2$ tahun). Sektor kerja terbagi menjadi sektor produktif dan non-produktif, mayoritas tenaga kerja wanita Indonesia bekerja di sektor non-produktif seperti pekerja rumah tangga dan rumahsakit. Sebagian besar partisipan penelitian memiliki pantangan makanan (78\%) dan memiliki pekerjaan sebelum mereka memutuskan untuk bekerja di Taiwan (68\%).

Tabel 1.

Karateristik Tenaga Kerja Wanita (TKW) Indonesia di Taiwan ( $\mathrm{N}=181)$

\begin{tabular}{ll}
\hline Karakteristik & $\boldsymbol{n}(\boldsymbol{\%})$ \\
\hline Personal characteristics & \\
\hline Usia (tahun) & $92(51)$ \\
$\quad<30$ & $70(39)$ \\
$30-39$ & $18(10)$ \\
$40-49$ & $73(40)$ \\
\hline Lulus SMA atau pendidikan tinggi & $102(56)$ \\
\hline Menikah & $123(68)$ \\
\hline Bekerja sebelum ke Taiwan & $142(78)$ \\
\hline Memiliki pantangan makanan & $113(62)$ \\
\hline Family characteristics & $49(27)$ \\
\hline Mempunyai anak & $86(47)$ \\
\hline Mempunyai anak usia 5 tahun ke bawah \\
(n=113) & $106(58)$ \\
\hline Pasangan memiliki pekerjaan & $75(42)$ \\
\hline Berkomunikasi rutin dengan keluarga & $0)$ \\
\hline Berkomunikasi tidak rutin dengan keluarga & \\
\hline Memiliki tanggungan & $93(51)$ \\
\hline Tidak memiliki tanggungan & \\
\hline Work characteristics & $9)$ \\
\hline Tempat kerja mengijinkan aktivitas sosial & \\
\hline Tempat kerja mengakomodasi pantangan & $3)$ \\
\hline makanan & $143(79)$ \\
\hline Lempat kerja mengakomodasi praktek agama & $97(54)$ \\
\hline Durasi kerja: Lebih dari 3 tahun & \\
\hline Sektor kerja: Non-produktif & \\
\hline
\end{tabular}


Berdasarkan informasi yang kami kumpulkan, penelitian ini adalah studi pertama yang menggunakan alat terstandardisasi untuk mengukur kondisi kesehatan mental tenaga kerja migran Indonesia di Taiwan. Prevalensi gejala depresi dan kecemasan dalam penelitian ini adalah $17 \%$. Prevalensi ini secara signifikan lebih tinggi daripada prevalensi kesehatan mental yang buruk pada populasi umum di Indonesia pada tahun 2013 (6\%) (Riskesdas, 2013). Patut dicatat bahwa penelitian acuan menggunakan alat ukur Strength and Difficulties Questionnaire (SDQ-20) untuk mengukur kesehatan mental prevalensi nasional, sementara penelitian ini menggunakan HSCL25. Namun, estimasi dari kedua instrumen masih sebanding (Ventevogel, 2007). Hasil penelitian ini juga dekat dengan hasil studi Dr. Lu pada tenaga kerja migran internal (dalam negeri) Indonesia yang menemukan bukti kuat bahwa individu migran secara signifikan lebih mungkin melaporkan gejala depresi dibandingkan dengan individu non-migran (Lu, 2010).

Hasil mengenai karakteristik individu tertera di Tabel 2. Terdapat hubungan negatif signifikan antara karakteristik 'memiliki anak' dan distres psikologis $(\mathrm{OR}=-0,157, \mathrm{p}<0.05)$, yang berarti bahwa partisipan yang memiliki anak memiliki distress psikologis yang lebih rendah dibandingkan partisipan yang tidak memiliki anak. Karakteristik lain seperti memiliki pantangan makanan, tingkat pendidikan dan status pernikahan tidak memiliki hubungan dengan distres psikologis. Keinginan untuk mencari kesempatan kerja yang lebih baik menurunkan kecenderungan distres psikologis yang tinggi. Dalam hal ini, dapat diamati bagaimana dinamika keluarga memengaruhi kesejahteraan tenaga kerja wanita Indonesia. Walaupun keluarga tetap merupakan unit terkecil dari konsep komunitas di Indonesia, struktur keluarga telah mengalami perubahan besar selama beberapa dekade terakhir. Struktur keluarga bergeser dari sistem keluarga besar tradisional ke sistem keluarga inti, atau lazim disebut nuclear family (Hugo, 1995; Hugo, 2002). Dalam sistem keluarga besar tradisional, loyalitas utama cenderung diarahkan kepada orangtua dan kepada anggota keluarga senior lainnya. sementara loyalitas utama dan kewajiban dalam sistem nuclear family cenderung diarahkan kepada pasangan dan anak-anak dari individu tersebut (Hugo, 2002). Seperti yang ditunjukkan oleh penelitian sebelumnya mengenai pekerja asing di Indonesia, sebagian besar pekerja migran melaporkan bahwa keluarga mereka mendorong dan mendukung mereka untuk bekerja di luar negeri guna membantu menambah pendapatan keluarga serta mengumpulkan dana untuk pendidikan anak-anak (Hugo, 1995). Dengan demikian, alasan bekerja untuk mencari kesempatan yang lebih baik bagi keluarga seseorang dapat memudahkan selama migrasi dan membantu adaptasi yang lebih baik terhadap kehidupan di negara asing.

Tabel 2.

Asosiasi Antara Karakteristik Individu dan Distres Psikologis pada TKW Indonesia di Taiwan

\begin{tabular}{|c|c|}
\hline & $\begin{array}{l}\text { Unadjusted } \\
\text { Coefficient }(95 \% \text { CI })\end{array}$ \\
\hline Menikah & $-0.093(-0.198-0.012)$ \\
\hline Lulus SMA atau pendidikan tinggi & $0.001(-0.111-0.112)$ \\
\hline Memiliki pantangan makanan & $-0.024(-0.152-0.104)$ \\
\hline Memiliki anak & $-0.157(-0.264-(-0.051))$ \\
\hline
\end{tabular}

Hasil analisis antara distress psikologis dengan karakteristik keluarga dapat dilihat di Tabel 3. Hasil penelitian ini menemukan hubungan negatif signifikan antara komunikasi rutin dengan keluarga dan distres psikologis $(\mathrm{OR}=-0.254, \mathrm{p}<0.05)$, yang artinya bahwa partisipan yang memiliki komunikasi rutin dengan keluarga memiliki distress psikologis yang lebih rendah dibandingkan partisipan yang tidak berkomunikasi rutin dengan keluarganya. Temuan ini 
konsisten dengan penelitian pada tenaga kerja migran rumah tangga yang berasal dari Filipina (Garey et al, 2016) dan tenaga kerja migran internal dari Cina (van der Ham et al., 2016). Komunikasi keluarga membantu mengobati rasa sedih dan kesepian yang timbul, sementara kurangnya komunikasi meningkatkan derita emosional yang ditimbulkan oleh jarak yang jauh dari keluarga yang dikasihi. Hal ini menunjukkan pentingnya dukungan keluarga bagi tenaga kerja migran wanita dalam mempertahankan kondisi kesehatan mental yang baik. Meskipun berada di tempat terpisah, ikatan keluarga sering kali tetap kuat dalam menghadapi proses penyesuaian yang harus dihadapi oleh individu pekerja di negara tujuan. Tenaga kerja migran sering terisolasi dari masyarakat lokal di negara tujuan. Dengan adanya kendala sosial dan budaya yang memisahkan mereka dengan masyarakat lokal, kontak dengan orang terdekat merupakan salah satu sumber dukungan dan penghiburan bagi tenaga kerja wanita Indonesia. Seperti halnya studi yang dilakukan oleh Lu pada tenaga kerja migran internal Indonesia yang menemukan bahwa dukungan sosial dari keluarga merupakan faktor penting untuk memoderasi dampak migrasi terhadap kesehatan mental di antara perempuan pekerja migran pedesaan-perkotaan Indonesia (Hugo, 1995). Pentingnya kontak keluarga juga menandakan adanya sarana komunikasi yang tersedia yang digunakan pekerja migran asing untuk mempertahankan ikatan mereka dengan keluarga (Schmalzbauer, 2004; Silveira, 1998). Teknik komunikasi modern memungkinkan keluarga untuk berbicara satu sama lain dengan mudah dan murah (Schmalzbauer, 2004).

Tabel 3.

Asosiasi Antara Karakteristik Keluarga dan Distres Psikologis pada TKW Indonesia di Taiwan

\begin{tabular}{lc}
\hline & $\begin{array}{l}\text { Unadjusted } \\
\text { Coefficient }(\mathbf{9 5 \%} \mathbf{C I})\end{array}$ \\
\hline $\begin{array}{c}\text { Komunikasi rutin dengan keluarga } \\
\text { Jumlah tanggungan }\end{array}$ & $\mathbf{- 0 . 2 5 4}(\mathbf{- 0 . 3 8 1 - ( - 0 . 1 2 6 ) )}$ \\
$1-2$ anggota keluarga & $-0.054(-0.235-0.126)$ \\
Lebih dari 2 anggota keluarga & $-0.121(-0.299-0.058)$ \\
Pasangan memiliki pekerjaan & $-0.060(-0.165-0.045)$ \\
Orangtua memiliki pekerjaan & $0.039(-0.109-0.186)$ \\
\hline
\end{tabular}

Di sisi lain, individu yang bekerja di tempat yang mengijinkan mereka untuk mengikuti kegiatan sosial di luar lingkungan kerja cenderung memiliki distress psikologis yang lebih rendah dibanding individu yang bekerja di tempat yang tidak mengijinkan aktivitas sosial $(\mathrm{OR}=-0.148$, $\mathrm{p}<0.05)$. Terlihat dari hasil yang tertera di Tabel 4 , individu yang aktif dalam kegiatan di komunitas/perkumpulan kecil cenderung memiliki distres psikologis yang rendah. Dapat diasumsikan bahwa adalah penting bagi tenaga kerja wanita Indonesia di Taiwan untuk menjadi bagian dari sebuah komunitas kecil serta menghabiskan waktu di dalam komunitas tersebut. Komunitas kecil yang dimaksud umumnya terdiri dari sesama pekerja migran wanita Indonesia yang berada di lingkungan yang sama. 
Tabel 4.

Asosiasi Antara Karakteristik Lingkungan Kerja dan Distres Psikologis pada TKW Indonesia di Taiwan

\begin{tabular}{ll}
\hline & $\begin{array}{l}\text { Unadjusted } \\
\text { Coefficient }(\mathbf{9 5 \%} \mathbf{C I})\end{array}$ \\
\hline Bekerja di Taipei (kota besar) & $0.015(-0.090-0.120)$ \\
$\begin{array}{l}\text { Bekerja di industri non-produktif } \\
\text { Alasan migrasi }\end{array}$ & $-0.164(-0.457-0.128)$ \\
$\quad \begin{array}{l}\text { Bekerja untuk kesempatan lebih baik } \\
\text { Kegiatan sosial }\end{array}$ & $\mathbf{0 . 2 3 2}(\mathbf{0 . 1 1 5}-\mathbf{0 . 3 4 8})$ \\
$\quad$ Aktif dalam komunitas kecil & $\mathbf{- 0 . 1 4 8}(\mathbf{- 0 . 2 5 3}-\mathbf{( - 0 . 0 4 2 )}$ \\
Aktif dalam komunitas agama & $-0.087(-0.254-0.080)$ \\
\hline
\end{tabular}

Terdapat beberapa catatan yang perlu diingat ketika menginterpretasi hasil penelitian ini. Pertama, penelitian ini bersifat cross-sectional sehingga unsur temporalitas dan kausalitas tidak dapat dipastikan. Studi longitudinal akan berguna dalam memberikan pengetahuan lebih lanjut tentang risiko dan faktor protektif kesehatan mental di populasi ini. Namun demikian, peserta penelitian kami memiliki proporsi yang serupa dari jenis kelamin dan karakteristik sektor kerja pada pekerja migran Indonesia di Taiwan, berdasarkan data dari Statistik Nasional Taiwan (11). Ini dapat membantu untuk menggeneralisasi perkiraan kami tentang prevalensi tekanan psikologis dan risiko terkait atau faktor perlindungan terhadap pekerja migran Indonesia di Taiwan.

\section{KESIMPULAN DAN SARAN}

Terdapat hubungan signifikan yang positif antara distress psikologis dengan karakteristik keluarga dan lingkungan kerja. Komunikasi rutin dengan keluarga, keaktifan di komunitas serta alasan bekerja berhubungan dengan kesehatan mental yang lebih baik pada pekerja migran wanita Indonesia di Taiwan. Sejauh ini, penelitian ini yang pertama menggunakan alat terstandarisasi untuk mengukur prevalensi tekanan psikologis dan faktor-faktor yang dikaji terkait dengan tekanan psikologis di kalangan pekerja migran Indonesia. Untuk kesehatan mental yang lebih baik, pekerja migran Indonesia di Taiwan perlu berkomunikasi secara teratur dengan keluarga mereka dan ditampung praktik keagamaan di lingkungan kerja. Hasilnya membantu mengenali kebutuhan untuk menciptakan tempat kerja yang ramah dan memastikan alat komunikasi untuk memperkuat ikatan keluarga bagi pekerja migran Indonesia. Secara keseluruhan, penelitian ini menunjukkan perlunya penelitian lebih lanjut tentang masalah kesehatan mental di antara pekerja migran Indonesia di Taiwan.

\section{Ucapan Terima Kasih}

Peneliti mengucapkan terimakasih kepada semua pihak yang terlibat dalam penelitian ini: dosendosen pembimbing, aktivis serta anggota komunitas pekerja migran Indonesia di Taipei, juga para aktivis organisasi pekerja migran asing di Kaohsiung; yang terakhir namun yang terpenting, peneliti mengucapkan terimakasih sebanyaknya kepada para partisipan penelitian yang sudah bersedia meluangkan waktu untuk berpartisipasi dalam penelitian ini, berbagi cerita dan pengalaman mereka yang memberi makna unik pada penelitian ini.

\section{REFERENSI}

Bhugra, D. (2004). Migration and mental health. Acta Psychiatrica Scandinavica, 109(4), 243258.

Chin, C. B. N. (1997). Walls of Silence and Late Twentieth Century Representations of the Foreign 
Female Domestic Worker: The Case of Filipina and Indonesian Female Servants in Malaysia. The International Migration Review. 31(2): 353-385.

Calderon J, R. B., Agunias DR. (2012). Asian labour migrants and health: exploring policy routes. A Joint Series of the IOM Regional Office for Asia and the Pacific and the Migration Policy Institute. Retrieved from www.migrationpolicy.org/pubs/MigrationandHealth.pdf.

Derogatis, L. R., Lipman, R. S., Rickels, K., Uhlenhuth, E. H., \& Covi, L. (1974). The Hopkins Symptom Checklist (HSCL): a self-report symptom inventory. Behavioral Science, 19(1): $1-15$.

Foreign Workers in Productive Industries and Social Welfare by Nationality: 2001-2015. (2015). Taiwan. Retrieved from http://statdb.mol.gov.tw/html/mon/c12030.htm.

Garey E, S. J., Hood RW, Agustiani H, Setiono K. (2016). Development and validation of Religious Attribution Scale: in association with religiosity and meaning in life among economically disadvantaged adolescents in Indonesia. Mental Health, Religion \& Culture, 8: 818-832.

Hugo, G. (1995). International labor migration and the family: some observations from Indonesia. Asian Pacific Migration Journal, 4(2-3): 273-301.

Hugo, G. (2002). Effects of international migration on the family in Indonesia. Asian Pacific Migration Journal, 11(1): 13-46.

International Labour Organization. (2015). ILO Global estimates on migrant workers: Results and Methodology - Special focus on migrant domestic workers. Retrieved from www.ilo.org/wcmsp5/groups/public/@dgreports/@dcomm/documents/publication/wcms 436343.pdf.

International Organization of Migration (IOM). (2012). Labor Migration and Human Development: Annual Review. Retrieved from www.iom.int/files/live/sites/iom/files/What-We-Do/docs/LHD-Annual-Review-2012.pdf.

Jurado D, A. R., Martinez-Ortega JM, Mendieta-Marichal Y, Gutierrez-Rojas L, Gurpegui M. (2017). Factors associated with psychological distress or common mental disorders in migrant populations across the world. Revista de Psiquiatría y Salud Mental, 10(1); 45-58.

Lan, P.-C. (2006). Global Cinderellas : migrant domestics and newly rich employers in Taiwan. Durham, NC: Duke University Press. United States.

Liang, L.-F. (2015). The distortions of care needs and medical professionalism: The ruling practices of migrant labor policy in Taiwan. Journal of Ageing Studies, 34: 29-37.

Loveband, A. (2004). Positioning the product: Indonesian migrant women workers in Taiwan. Journal of Contemporary Asia, 34(3): 336-348.

Lu, Y. (2010). Mental health and risk behaviours of rural-urban migrants: Longitudinal evidence from Indonesia. Population Studies (Camb), 64(2): 147-163.

National Institute of Health Research and Development. (2013). National Health Research Report. Ministry of Health. Indonesia. Retrieved from http://labdata.litbang.depkes.go.id/risetbadan-litbangkes/menu-riskesnas/menu-riskesdas/374-rkd-2013.

Schmalzbauer, L. (2004). Searching for Wages and Mothering from Afar: The Case of Honduran Transnational Families. Journal of Marriage and Family, 66(5): 1317-1331.

Silveira, E. R., \& Ebrahim, S. (1998). Social determinants of psychiatric morbidity and well-being in immigrant elders and whites in east London. International Journal of Geriatric Psychiatry, 13(11): 801-812.

Turnip, S. S., \& Hauff, E. (2007). Household roles, poverty and psychological distress in internally displaced persons affected by violent conflicts in Indonesia. Social Psychiatry Psychiatric Epidemiology, 42(12): 997-1004.

Turnip, S. S., Klungsoyr, O., \& Hauff, E. (2010). The mental health of populations directly and indirectly exposed to violent conflict in Indonesia. Conflict and Health, 4: 14. 
United Nations, Department of Economic and Social Affairs, Population Division. (2016). International Migration Report 2015: Highlights (ST/ESA/SER.A/375). Retrieved from www.un.org/en/development/desa/population/migration/publications/migrationreport/doc s/MigrationReport2015_Highlights.pdf.

van der Ham, A. J., Ujano-Batangan, M. T., Ignacio, R., \& Wolffers, I. (2016). The dynamics of migration-related stress and coping of female domestic workers from the Philippines: an exploratory study. Community Mental Health Journal, 51(1):14-20.

Ventevogel, P., De Vries, G., Scholte, W. F., Shinwari, N. R., Faiz, H., Nassery, R., Olff, M. (2007). Properties of the Hopkins Symptom Checklist-25 (HSCL-25) and the SelfReporting Questionnaire (SRQ-20) as screening instruments used in primary care in Afghanistan. Social Psychiatry Psychiatric Epidemiology, 42(4): 328-335.

World Bank. International Migration and Development in East Asia and the Pacific. (2014). Retrieved from https://openknowledge.worldbank.org/handle/10986/20437? show=full.

World Health Organization. (2001). Mental Health: New Understanding, New Hope. Retrieved from http://www.who.int/whr/2001/en/. 